\title{
Dipeptidyl Peptidase-4 Inhibitor Sitagliptin Attenuates Arterial Calcification By Downregulating Oxidative Stress-Induced Receptor for Advanced Glycation End Products in Low-Density Lipoprotein Receptor Knockout Mice
}

Chih Pei Lin ( $\nabla$ cplin@tzuchi.com.tw)

Taipei Tzu Chi Hospital

\section{Po-Hsun Huang}

Institute of Clinical Medicine, National Yang Ming Chiao Tung Universisty

Chi-Yu Chen

Institute of Clinical Medicine, National Yang Ming Chiao Tung University

Jia-Shiong Chen

Institute of Clinical Medicine, National Yang Ming Chiao Tung University

Jaw-Wen Chen

Division of Cardiology \& Healthcare and Management Center, Taipei Veterans General Hospital

Shing-Jong Lin

Division of Cardiology, Taipei Veterans General Hospital

Original investigation

Keywords: Arterial Calcification, Diabetes, Dipeptidyl Peptidase-4 Inhibitor, Oxidative Stress, Receptor for Advanced Glycation End products

Posted Date: May 11th, 2021

DOI: https://doi.org/10.21203/rs.3.rs-498043/v1

License: (c) (i) This work is licensed under a Creative Commons Attribution 4.0 International License.

Read Full License 


\section{Abstract}

Background:Plasma advanced glycation end products (AGEs) activates the receptor for advanced glycation end products (RAGE) and the activation of RAGE is implicated to be the pathogenesis of type 2 diabetic mellitus patient vascular complications. Attenuating the activation of RAGE may exert a protective effect against the development of cardiovascular disease. Dipeptidyl peptidase-4 (DPP4) inhibitors are a new class of oral hypoglycemic agents for the treatment of type 2 diabetes mellitus. Whether sitagliptin, a DPP-4 inhibitor, has a beneficial effect on vascular calcification remains undetermined.

Methods: In the present study, we fed low-density lipoprotein receptor knockout (LDLR ${ }^{-/}$) mice a high fat diet to induce diabetic mellitus and studied the effect of orally administered sitagliptin on the high fat diet fed $\mathrm{LDLR}^{-/-}$mice aorta medial calcification, RAGE expression, oxidative stress, aorta calcium content. Tumor necrosis factor (TNF)-a combined with S100A12 was used to induce HASMC oxidative stress, activation of NADPH, up-regulation of the bone markers and RAGE expression, and cell calcium deposition. Effect of sitagliptin, siRNA for RAGE and apocynin on blunting TNF-a and S100A12 induced HASMC oxidative stress, calcification and NADPH activation were also investigated.

Results: Sitagliptin attenuated the HFD-induced $\mathrm{LDLR}^{-/-}$mice hyperlipidemia, hyperglycemia, increase in serum TNF-a, aorta calcium deposition and the expression of RAGE in the medial layer of the aorta. TNFa combined with S100A12 stimulated HASMC RAGE expression, calcium deposition, nicotinamide adenine dinucleotide phosphate (NADPH) oxidase (Nox) activation, and up-regulation of bone marker (bone morphogenetic protein-2, Msh homeobox 2, and runt-related transcription factor 2) expression. Sitagliptin and apocynin (APO), an NADPH oxidase inhibitor, suppressed the TNF-a+S100A12 treatment effects on the activation of NADPH oxidase and Nuclear factor (NF)-KB and the resultant oxidative stress, up-regulation of RAGE and bone markers expression and calcium deposition. Our findings suggest that sitagliptin imparts its protective effect by suppressing NADPH oxidase and NF-KB activation to blunt the up-regulation of RAGE expression.

Conclusion: Our findings suggest that sitagliptin may suppress the initiation and progression of artery calcification by inhibiting the activation of NADPH oxidase and NF-KB and the resultant up-regulation of expression of RAGE.

\section{Background}

Type 2 diabetes mellitus (DM2) patients have a higher risk of developing atherosclerosis, artery calcification, morbidity and mortality rates than non-diabetic population $[1,2]$. The mechanism causing the DM2 patients to have a higher risk of vascular calcification is not yet fully understood. Hyperglycemia and hyperlipidemia are suggested to be the major risk factors [3]. The pathogenesis of artery calcification involves various types of cells and complicated regulated processes. Smooth muscle cells (SMCs), are believed to be involved in the pathogenesis of vascular calcification [4]. Medial calcification represents a 
concentric calcification that is preceded by matrix vesicle-nucleated mineralization accompanied with calcium phosphate deposits in the arterial tunica media [5]. Multiple factors, such as inflammation, oxidative stress, adiposity, insulin resistance, and advanced glycation end-products, contribute to the induction and progression of diabetic medial calcification [6-8]. Important transcription factors, such as Msh homeobox 2 (MSX2), Osterix, and runtrelated transcription factor 2 (RUNX2), are crucial in the programing of osteogenesis $[9,10]$. Currently, no therapy is available to reverse the vascular calcification. Understanding the association between the DM complications and HASMC osteotransformation could aid the development of anti- artery calcification therapeutics.

In addition to elevated bone matrix protein (BMP) expression and calcium phosphate deposit in vascular SMCs (VSMCs), diabetic patients also have a higher level of plasma advanced glycation end products (AGEs) and receptors for AGEs (RAGEs) than the nondiabetic population $[8,11]$. AGEs activate RAGE and AGE/RAGE signaling enhances VSMC calcification by activation of nicotinamide adenine dinucleotide phosphate (NADPH) oxidase (Nox) 1 pathway [12]. Recent studies suggested that DM2 patients has a higher level of circulatory S100A12, a RAGE agonist than the non-diabetic person [13]. This RAGES100A12 interaction is implicated to cause coronary artery diseases and vascular calcification $[14,15]$. The RAGE is expressed in endothelial and smooth muscle cell (SMC), and the activation of RAGE augments inflammation by stimulating the release of inflammatory cytokines and generation of oxidative stress [16]. It was found that S100A12 transgenic apolipoprotein-E (ApoE) null mice on regular rodent chow developed much more server calcified atherosclerotic plaques and medial calcification than the wild type ApoE null animal [14]. The authors concluded that the RAGE/S100A12 signaling play a significant role in the diabetic artery atherosclerosis and calcification. It is suggested that the activation of RAGE activates nuclear factor (NF)-KB which leads to a wide spectrum of pathological inflammation conditions and results in various diseases such as atherosclerosis [17]. The activation of NF-KB also upregulates RAGE expression and this positive feedback loop of between RAGE and NF-KB signaling pathway results in a perpetuation of inflammation state[18]. AGEs, amyloid beta peptide, DNA-binding protein high-mobility group box-1/amphoterin, and S100/calgranulins activate RAGE and NF-KB [18]. A previous study using transgenic human S100A12 CLB6/J mice to investigate the role of S100A12 on artery calcification using a chronic kidney disease mouse model [19]. This study showed that the oxidative stress induced by ureteral obstruction played a critical role for the RAGE/S100A12 signaling to induce aorta calcification.

Dipeptidyl peptidase-4 (DPP-4) is a multifunctional enzyme found in catalytically active soluble form in plasma and on the surface of most cell types [20]. DPP4 knockout mice study revealed that the absence of this enzyme improves glycemic control and reduces animal fat mass [21]. DPP4 degrades incretin hormones, such as type I glucagon-like peptide (GLP-1) that is widely known for its regulatory effect in glucose metabolism [22]. DPP4 inhibitors are a new class of oral hypoglycemic agents used for the treatment of type 2 diabetes mellitus without causing weight gain [23]. Sitagliptin and alogliptin improve endothelial function and impart an anti-inflammatory effects which is suggested to retard the progression of carotid atherosclerosis in DM2 patients [24, 25]. Sitagliptin and alogliptin were reported to inhibit the progression of atherosclerosis in ApoE-deficient mice $[26,27]$. Recent animal studies suggest that DPP4 
inhibitor may contribute its anti-atherosclerotic effects by reducing the reactive oxygen species (ROS) generation, preventing mitochondrial depolarization, improving endothelial functions, and reducing vascular inflammation [28]. Hyperglycemia and dyslipidemia are known risk factors associated with artery calcification. Thus, DPP4 inhibitor treatment may blunt the development of atherosclerosis in diabetic patients. Gemigliptin was found to protect against vascular calcification in a adenine induced chronic kidney disease rat model and phosphate induced VSMC calcification [29]. It was reported that TNF-a play a crucial role in artery calcification in diabetes $\mathrm{LDLR}^{-/-}$mice [7]. Our previously study showed that tumor necrosis factor (TNF-a) and vascular TNF receptor (TNFR) signaling lead to human artery smooth muscle cell (HASMC) calcification and antioxidants blunt the TNF-a/TNFR signaling to retard the HASMC calcification [30]. We hypothesized that the hyperglycemia and hyperlipidemia of the DM2 patients induce systematic oxidative and the resultant elevation of circulatory (TNF)-a and S100A2 triggers the vascular calcification. Sitagliptin may improve the DM2 patient artery calcification by either improve the patient hyperglycemia and hyperlipidemia conditions or by functioning as an antioxidant to bunt TNF-a/TNFR signaling. In this study, we used HFD to induce diabetic condition in LDLR ${ }^{-/-}$mice to study the effect of orally administered sitagliptin on the artery calcification and RAGE expression. We use TNF- $a+$ S100A12 treated cultured HASMCs as a model system to study how the systemic inflammation affect DM2 patient aorta calcification. We also explored the possible mechanisms by which sitagliptin contributes its protective effects.

\section{Materials And Methods}

\section{Materials}

Human SMC growth medium (M231), smooth muscle growth supplement, trypsin/ethylenediaminetetraacetic acid (EDTA) solution, trypsin neutralizer solution, and HASMCs were obtained from Cascade Biologics (Portland, OR). Fetal bovine serum (FBS), antibiotic-antimycotic mixture, mouse TNF-a kits, oligofectamine, and 2',7'-dichlorofluorescein diacetate were obtained from Life Technology (Grand Island, NY). Small interfering RNA (siRNA) oligonucleotides against RAGE and antibodies against human TNFR1 (sc-8436), MSX2 (sc-17729), BMP2 (sc-6895), RUNX2 (sc-10758), CD68 (sc-9139), $\beta$-actin (sc-47778), and anti-hnRNP c1/c2 (sc-32308) were obtained from Santa Cruz Biotechnology (Santa Cruz, CA). Antibodies against human, Nox subunit p47 (\#610354), and caveoli-1 (\#610406) were obtained from BD Biosciences (San Jose, CA). Unless otherwise specified, all other chemicals and reagents obtained from Sigma-Aldrich (St. Louis, MO).

\section{Animal study}

Weaned male low-density lipoprotein receptor knockout $\left(\mathrm{LDLR}^{-/-}\right)$mice (Jackson Labs \#002207; C57BL/6J background) were fed with a normal diet (Picolab Rodent Diet 20 \#5053: 5\% fat, 21\% protein, $3.3 \%$ sucrose, and $28 \%$ starch) for 2 months then the animals were randomized into 3 groups: 1 ) normal diet group, 2) high fat diet (HFD) Harlan Teklad, Diet TD88137 (21\% milk fat (42\% fat calories), 34\% sucrose, and $0.15 \%$ cholesterol)) group and 3) HFD + sitaglptin group. Animals in group 2 are gavaged 
with $100 \mu \mathrm{L}$ of distilled water daily. Animals in group 3 were given $100 \mathrm{mg}^{-1} \mathrm{Kg}^{-1} \mathrm{day}^{-1}$ of sitagliptin by gavaging various amount of sitagliptin solution $(25 \mathrm{mg} / \mathrm{mL})$ (BioVision Research Products, Milpitas, CA). All mice were kept in microisolator cages under a $12 \mathrm{~h}$ day/night cycle. The entire animal was given free access to chow and water. All animal study protocols complied with the Guide for the Institutional Animal Care and Use Committee of Taipei Veterans General Hospital (IACUC no.2020 - 265, Taipei, Taiwan) and the Guide for the Care and Use of Laboratory Animals of the US National Institutes of Health (8th edition, 2011). The $\mathrm{LDLR}^{-/-}$mice were sacrificed after 24 weeks of treatments by exsanguination under anesthesia (100 mg-1 $\mathrm{kg}^{-1}$ ketamine- $\mathrm{HCl}$ and $20 \mathrm{mg}^{-1} \mathrm{~kg}^{-1}$ xylazine via IP injection) after 6 hours fasting. The animals were considered as adequately anesthetized when no attempt to withdraw the limb after pressure could be observed. The thoracic cavity was opened for blood and aorta (from heart to diaphragm) sample collections.

\section{Histology and immunohistochemistry}

Aorta samples were cut into 4 sections and processed for histological staining as described in our previous study[30]. Paraffin sections $(5 \mu \mathrm{m})$ from the dissenting aorta were stained using various agents for semi-quantification of atherosclerotic lesion size and severity (hematoxylin and eosin (H\&E) staining) and aortic calcium deposition (alizarin red S staining). Immunohistochemical (IHC) staining of RAGE and VSMC actin (SM a-actin) was performed as previously described [31].

\section{Cell cultures and cell viability assay}

HASMCs were purchased from Life Technology (Grand Island, NY. catalog number C0075C). The cells were grown and passaged as described previously[30]. Briefly, the HASMCs were grown in M231 medium containing SMC growth supplement and a $1 \%$ antibiotic-antimycotic mixture in an atmosphere of $95 \%$ air and $5 \% \mathrm{CO}_{2}$ at $37^{\circ} \mathrm{C}$ in plastic flasks. At confluence, the cells were subcultured at a ratio of $1: 3$, and passages 3 through 8 were used. The cytotoxicity of S100A12 protein and sitagliptin on HASMC cell viability were measured with the 3-(4,5-dimethylthiazol-2-yl)-2, 5-diphenyl tetrazolium bromide (MTT) assay.

\section{Soluble DPP-4 activity measurement}

Serum DPP-4 activity was measured using the Enzyme-linked immunosorbent assay (ELISA)-Kit from Abcam (Abcam, Cambridge, MA, USA, ab22287) according to the manufacturer's instructions.

\section{Quantification of aorta or cultured HASMC calcium deposit}

Cultured cell Ca content was determined using a BioChain Calcium Kit (BioChain, Hayward, CA, USA) as previously described[32]. Briefly, the 6 well plate cultured cells were counted and demineralized with 250 $\mu l 0.6 \mathrm{~N} \mathrm{HCl}$ for $12 \mathrm{~h}$. A working reagent was prepared by mixing $75 \mu$ reagent $A$ and $75 \mu \mathrm{l}$ reagent $B$ and was equilibrated to room temperature before use. A volume of $50 \mu$ diluted standards or samples were transferred to each well of a clear-bottom 96 -well plate. Then, $200 \mu$ l working reagent was added, and the solution was mixed by light tapping. After incubation for $3 \mathrm{~min}$ at room temperature, absorbance was measured at 570-650 $\mathrm{nm}$ with a $96-$ well reader. The units of these results are $\mathrm{ug} / \mathrm{mL}$ calcium. The other 
6 well plate cultured cells counted and solubilized in $200 \mu$ lysis solution containing $0.1 \mathrm{~N} \mathrm{NaOH}$ and $0.1 \%$ sodium dodecyl sulfate (SDS) at room temperature for $5 \mathrm{~min}$. Protein concentration was measured with a Bio-Rad DC Protein Assay Kit. The calcium content of the cultured cells normalized to the protein content was reported.

The aortic segments from experimental mice were extracted using $0.6 \mathrm{~N} \mathrm{HCl}$ for $24 \mathrm{~h}$ and the calcium content of the extracts were determined using a BioChain Calcium Kit (BioChain, Hayward, CA, USA) as previously described[30]. The results were expressed as $\mu \mathrm{g} / \mathrm{mg}$ of wet aortic tissues.

\section{Extraction of cellular proteins}

Nuclear protein extracts were prepared as previously described[33]. In brief, after cells were washed twice using a ice-cold PBS, they were scraped off the plates with a cell scraper and dispersed in $1 \mathrm{~mL}$ ice-cold buffer A (10 mM HEPES/ $\mathrm{NaOH}, \mathrm{pH} 7.9,10 \mathrm{mM} \mathrm{KCl}, 1.5 \mathrm{mM} \mathrm{MgCl}, 1 \mathrm{mM}$ dithiothreitol [DTT], $0.5 \mathrm{mM}$ phenylmethylsulfonyl fluoride (PMSF), $2 \mu \mathrm{g} / \mathrm{mL}$ aprotinin, $2 \mu \mathrm{g} / \mathrm{mL}$ pepstatin, and $2 \mu \mathrm{g} / \mathrm{mL}$ leupeptin). Cells were harvested after centrifugation at $500 \cdot \mathrm{g}$ for $10 \mathrm{~min}$ at $4^{\circ} \mathrm{C}$ then cells were re-suspended in $80 \mu \mathrm{l}$ buffer B (buffer A containing $0.1 \%$ Triton X-100) by gentle pipetting. The cell lysates were allowed to stand on ice for $10 \mathrm{~min}$ and then centrifuged at $12,000 \cdot \mathrm{g}$ for $10 \mathrm{~min}$ at $4^{\circ} \mathrm{C}$. Nuclear pellets were resuspended in $70 \mu$ ice-cold buffer $\mathrm{C}\left(20 \mathrm{mM} \mathrm{HEPES} / \mathrm{NaOH}, \mathrm{pH} 7.9 ; 1.5 \mathrm{mM} \mathrm{MgCl}_{2} ; 1 \mathrm{mM}\right.$ DTT; $0.2 \mathrm{mM}$ EDTA; 420 mM NaCl; 25\% glycerol; 0.5 mM PMSF; $2 \mu \mathrm{g} / \mathrm{mL}$ aprotinin; $2 \mu \mathrm{g} / \mathrm{mL}$ pepstatin; $2 \mu \mathrm{g} / \mathrm{mL}$ leupeptin), incubated on ice for $30 \mathrm{~min}$ with intermittent mixing, and then centrifuged at $15,000 \cdot \mathrm{g}$ for 30 $\min$ at $4^{\circ} \mathrm{C}$.

Cell membrane fractions were prepared as described previously[30] with some modifications. Briefly, HASMCs were lysed in a lysis buffer (10 mM Tris-HCl, 1 mM EDTA, 1 mM PMSF, $10 \mu \mathrm{g} / \mathrm{mL}$ aprotinin, and $0.5 \mu \mathrm{g} / \mathrm{mL}$ leupeptin; $\mathrm{pH}$ 7.5). The cell lysates were centrifuged at $3000 \cdot \mathrm{g}$ for $20 \mathrm{~min}$. Pellets were resuspended in lysis buffer $(20 \mathrm{mM}$ Tris- $\mathrm{HCl}, 150 \mathrm{mM} \mathrm{NaCl}, 1 \mathrm{mM}$ EDTA, $1 \mathrm{mM}$ ethylene glycol tetraacetic acid, $1 \%$ Triton, $2.5 \mathrm{mM}$ sodium pyrophosphate, $1 \mathrm{mM} \beta$-glycerophosphate, $1 \mathrm{mM} \mathrm{Na}_{3} \mathrm{VO}_{4}, 1 \mu \mathrm{g} / \mathrm{mL}$ leupeptin, and $1 \mathrm{mM} \mathrm{PMSF}$; pH 7.5) and designated as the membrane fraction.

Total cell lysates were prepared in lysis buffer (20 mM Tris-HCl, $150 \mathrm{mM} \mathrm{NaCl}, 1 \mathrm{mM}$ EDTA, $1 \mathrm{mM}$ ethylene glycol tetraacetic acid, $1 \%$ Triton, $2.5 \mathrm{mM}$ sodium pyrophosphate, $1 \mathrm{mM} \beta$-glycerophosphate, 1 $\mathrm{mM} \mathrm{Na}_{3} \mathrm{VO}_{4}, 1 \mu \mathrm{g} / \mathrm{mL}$ leupeptin, and $1 \mathrm{mM} \mathrm{PMSF} ; \mathrm{pH}$ 7.5). The protein concentrations were determined with Bio-Rad Protein Assay Reagent (Bio-Rad, Hercules, CA), and the samples were stored at $-70^{\circ} \mathrm{C}$.

\section{Western blot analysis (see previous comment)}

Western blot analysis was used to quantify the HASMC nuclear and cytosol of the Nox p47phox, NF-KB p65, nuclear MSX-2, BMP-2 and RUNX2. Proteins of interest were isolated by SDS polyacrylamide gel and transferred to polyvinylidene fluoride membranes (PVDF, Millipore, Bedford, MA). The PVDF were blocked with $5 \%$ milk solution (Skimmed instant milk powder with PBS-T) then probed with anti-p47phox, antiTR1, anti-p65, goat anti-MSX-2, BMP-2, or RUNX2 (1:1000) antibodies. Then they were incubated with horseradish peroxidase-conjugated secondary antibodies. The proteins were visualized using an 
enhanced chemiluminescence detection kit (Amersham Biosciences, Piscataway, NJ). Anti- $\beta$-actin (1:5000), anti-caveolin-1 (1:1000), and anti-hnRNP c1/c2 (1:1000) antibodies were used as loading controls. Protein expression levels were quantified as optical densities using ImageQuant software v.5.2.

\section{Nox activity assay and hydrogen peroxide determination}

Nox activity was determined with superoxide-dependent lucigenin chemiluminescence, as previously described[30]. Confluent HASMCs in 6-well plates were pretreated with various concentrations of antioxidant reagents followed by treated TNF- $a+S 100 A 12$ with or without sitagliptin for 1 day. Cell membrane extract $(40 \mu \mathrm{g})$ and $5 \mu \mathrm{M}$ dark-adapted lucigenin were added to a 96-well luminometer plate and adjusted to a final volume of $250 \mu$ l with oxidase assay buffer before $100 \mu \mathrm{M}$ NADPH was added. Relative light units (RLUs) were measured with a luminometer (Dynatech ML2250, Dynatech Laboratories Inc., VA). Light emission was recorded every 3 minutes for total 30 minutes and expressed as mean $\mathrm{RLUs} / \mathrm{min}$.

The ROS production in HASMCs was determined by fluorometric assay using dichloro-dihydro-fluorescein diacetate (DCFH-DA) as the probe. This method is based on the oxidation by $\mathrm{H}_{2} \mathrm{O}_{2}$ of nonfluorescent DCFH-DA to fluorescent 2',7'- dichlorofluorescin. Confluent HASMCs in 24-well plates were pretreated with various concentrations of antioxidant reagents followed by treated TNF-a + S100A12 with or without sitagliptin for 1 day. The cells were washed with PBS, then $250 \mu \mathrm{L}$ of serum-free M231 containing $10 \mu \mathrm{M}$ DCFH-DA was added to the well for 30 minutes. The fluorescence intensity (relative fluorescence units) was measured at $485 \mathrm{~nm}$ excitation and $530 \mathrm{~nm}$ emission using a fluorescence microplate reader after the plates are incubated for $45 \mathrm{~min}$ at $37^{\circ} \mathrm{C}$.

\section{siRNA transfection}

siRNA oligonucleotides against RAGE were suspended in RNase-free water at a concentration of $10 \mu \mathrm{M}$. Cells were seeded one day before transfection to ensure HASMC were $85-95 \%$ confluent on the day of transfection. For transfection, the regular cell culture medium was replaced with a serum-free medium without antibiotics. The cells were transfected with siRNA using oligofectamine at a ratio of 1 siRNA: 2 oligofectamine $(\mu \mathrm{g}: \mu \mathrm{l})$ at a final concentration of 25-50 nM siRNA. The cells were incubated with the siRNA-oligofectamine complex for $5 \mathrm{~h}$. Then, the serum-free medium was replaced with a normal medium (containing 10\% FBS) without antibiotics, and the cells were incubated for $48 \mathrm{~h}$ before further analysis.

\section{Statistical analyses}

Data were expressed as means \pm standard deviation (SD). Statistical evaluation was performed using Student's $t$-test or one-way analysis of variance, followed by Dunnett's test. A $P$ value of $<0.05$ was considered significant.

\section{Results}


Effect of HFD and Sitagliptin on HFD-induced LDLR $^{-/-}$body weight gain, aortic calcification and Atherosclerotic plaque formation.

We found that HFD LDLR ${ }^{-/-}$mice has a significant higher body weight than the regular chow fed ones $(33.8 \pm 1.9$ VS. $41.8 \pm 2.3$ g). Sitagliptin attenuated HFD-induced body weight gain (Fig. 1a; $41.8 \pm 2.3$ VS. $36.8 \pm 2.5 \mathrm{~g}$ ). HFD fed animals has a higher level of blood glucose, triglyceride (TG), cholesterol (CHL), low-density lipoproteins (LDL) and TNF-a than the regular chow fed animals (Table 1). These findings suggest that HFD fed $\mathrm{LDLR}^{-/-}$mouse is a valid model as an obesity-associated type II diabetes animal model. Sitagliptin treatment moderately lowered the HFD fed animal blood glucose but drastically lowered the fasting triglyceride (TG) (539 $\pm 121 \mathrm{VS} .358 \pm 128 \mathrm{mg} / \mathrm{dL})$ and TNF-a level (53 $\pm 17 \mathrm{VS} .30 \pm 7$ $\mathrm{pg} / \mathrm{mL}$ ). Numerically, a moderate reduction in LDL was observed, but the level of reduction is not statistically significant.

Table 1

Metabolic parameters after 24 weeks of dietary challenge and sitagliptin $(100 \mathrm{mg} / \mathrm{kg} / \mathrm{day})$ treatment.

\begin{tabular}{|llll|}
\hline & $\begin{array}{l}\text { Chow } \\
(\mathbf{n}=6)\end{array}$ & $\begin{array}{l}\text { HFD + Vehicle } \\
(\mathbf{n}=6)\end{array}$ & $\begin{array}{l}\text { HFD + Sitagliptin } \\
(\mathbf{n}=6)\end{array}$ \\
\hline Calcium $(\mathrm{mg} / \mathrm{dL})$ & $8.8 \pm 0.6$ & $8.8 \pm 0.2$ & $9.1 \pm 0.1$ \\
\hline PHOS $(\mathrm{mg} / \mathrm{dL})$ & $8 \pm 1$ & $7.5 \pm 0.2$ & $7.0 \pm 1.0$ \\
\hline Glucose $(\mathrm{mg} / \mathrm{dL})$ & $105 \pm 15$ & $274 \pm 31^{*}$ & $223 \pm 22^{\#}$ \\
\hline CHOL $(\mathrm{mg} / \mathrm{dL})$ & $255 \pm 42$ & $1098 \pm 273^{*}$ & $1105 \pm 135$ \\
\hline HDL $(\mathrm{mg} / \mathrm{dL})$ & $60 \pm 22$ & $65.0 \pm 15.0^{\star}$ & $65.0 \pm 2.0$ \\
\hline LDL $(\mathrm{mg} / \mathrm{dL})$ & $91 \pm 27$ & $566 \pm 166^{\star}$ & $463 \pm 68$ \\
\hline TG $(\mathrm{mg} / \mathrm{dL})$ & $117 \pm 32$ & $539 \pm 121^{*}$ & $358 \pm 128^{\#}$ \\
\hline TNF-a $(\mathrm{pg} / \mathrm{mL})$ & $10.8 \pm 6.4$ & $55.3 \pm 17.5^{\star}$ & $30.5 \pm 7.7^{\#}$ \\
\hline Nitrotyrosin $(\mathrm{ug} / \mathrm{mL})$ & $9.9 \pm 4.6$ & $34.8 \pm 2.6^{*}$ & $10.5 \pm 4.5^{\#}$ \\
\hline
\end{tabular}

HFD-fed LDLR ${ }^{-/-}$mice had a remarkable increase in calcification in the medial layer of the upper descending aorta as indicated by alizarin red staining and aorta calcium content analysis (Fig. 1b and 1c) compared to the regular chow fed animals. HFD also caused the $\mathrm{LDLR}^{-/-}$mice to have a much higher serum DPP4 activity (Fig. 1d). Sitagliptin treatment significantly blunted the HFD induced calcium deposition in the media of the descending aorta (Fig. 1b), aorta acid extract $\mathrm{Ca}$ (Fig. 1c) and serum DPP4 activity (Fig. 1d). Our findings showed that HFD causes the $\mathrm{LDLR}^{-/-}$to become obsess, hyperglycemic and hyperlipidemic which lead to oxidative stress and elevated TNF-a. (*your data showed that is what happened). The elevated TNF-a may induce a cascade of events leads to the initiation and propagation 
of artery atherosclerotic plaque formation and artery calcification. Sitagliptin protected the HFD fed $\mathrm{LDLR}^{-/-}$mice from developing severe artery calcification. Our findings suggest a possibility that sitagliptin may protect the obese type 2 DM patients against the initiation and progression of atherosclerotic plaque formation and aorta calcification for by blunting the cascade of events induced by the elevated TNF-a.

\section{Effect of TNF-a and S100A12 on HASMC cell RAGE expression and calcium deposition}

It is known that obese type 2 DM patients has higher levels of TNF-a and S100A12 compared to nondiabetic subjects[34]. The S100A12/RAGE signaling is associated with the severity of coronary artery diseases and vascular calcification of the type 2 diabetes mellitus patients [14, 15]. We use human artery smooth muscle cells (HASMC) model to investigate 1) if TNF- $-\mathrm{S}$ S100A12 treatment affect HASMC calcification and 2) if and how sitagliptin blunts the effect of TNF-a + S100A12 treatment. We found that TNF-a $(10 \mathrm{ng} / \mathrm{mL})$ treatment significantly increased the HASMC S100A12 expression (Fig. 2a). This finding suggests that TNF-a may induce a pathological condition for the HASMC to express S100A12. Under physiological condition, S100A12 is mainly expressed by the myeloid cells. However, under a pathological condition such as coronary artery plaque rupture, S100A12 is expressed in HASMC [35]. Incubating HASMC with S100A12 did not significantly increase the HASMC S100A12 expression (Fig. 2a). It is possible that the S100A12 may have activated the HASMC RAGE to trigger a cascade of events results in a small increase in S100A12 expression but the increase did not reach statistically significant level (Fig. 2a). Before we investigate effect of S100A12 on HASMC RAGE expression, we investigate the toxicity of S100A12 treatment. We found that S100A12, up to $200 \mathrm{ng} / \mathrm{ml}$ level, did not impair the HASMC cell vitality as indicated by cell proliferation rate (Fig. 2b). Incubating HASMC with increasing level of S100A12 produced a dose dependent increase in HASMC RAGE expression (Fig. 2c). Our data suggest that the S100A12 in the medium activated the HASMC RAGE which then triggered a mechanism to up-regulate the HASMC RAGE expression. It was reported that RAGE signaling leads to activation of NF-KB and activation of NF-KB stimulates RAGE expression [18]. In the presence of TNF-a (10 ng/mL), S100A12 produced a much more pronounced dose response on HASMC RAGE expression (Fig. 2c). Figure $2 \mathrm{~d}$ showed that the potency of S100A12 treatment on HASMC calcium deposits were much more pronounce in the presence of TNF-a. Previous study from this laboratory showed that incubating HASMC with TNF-a activate NF-KB as indicated by the increase in P65 in the HASMC nucleus [7]. Figure $2 \mathrm{c}$ and $2 \mathrm{~d}$ suggest that RAGE/S100A12 and NF-KB forms an perpetual amplifying loop as suggested by literature [18]. It was proposed that activation of RAGE results in oxidative stress which lead to activation of NF-KB and the activated NF-KB stimulates more RAGE expression to form a perpetual amplifying loop between S100A12 [18].

Effect of sitagliptin, N-acetyl cysteine (NAC), small interfering RNA (siRNA) for TNF receptor 1 (TNFR-1) and Si RNA for RAGE on the TNF-a plus S100A12 treated HSMC RAGE expression and calcium 
It has been reported that that tenegliptin, a DPP4 enzyme inhibitor, have anti-atherosclerotic effects by reducing the production of reactive oxygen species (ROS) and inflammatory cytokines in adipocytes and aorta [28]. The authors suggested that there may be a not yet fully understood GLP-1 independent mechanism that also contributed to the DPP4 inhibitor anti-atherosclerotic effect. Our LDLR ${ }^{-/-}$mice study showed that Sitagliptin only produced a small reduction of the HFD fed LDLR ${ }^{-/-}$mice serum glucose and LDL level yet it is very effective in protecting the HFD fed $\mathrm{LDLR}^{-/-}$mice from developing aorta calcification (Fig. 1 and Table 1). Previous study from this lab showed that $\mathrm{N}$-acetyl cysteine (NAC) and APO were very effective in reducing the serum nitrotyrosin and aorta calcium deposit of the HFD fed $\mathrm{LDLR}^{-/-}$mice [30]. It was proposed that the RAGE signaling was at least in part mediated by the oxidative stress from NADPH oxidase [18]. It is possible that Apo inhibits the NADPH oxidase activity and NAC neutralized the ROS produced by NADPH oxidase to exert their protective effect on HFD induced aorta calcification observed in our previous study. We further speculated that sitagliptin may 1) function as an anti-oxidant to neutralize the oxidative stress induced by HFD and/or 2) it may inhibit the NADPH oxidase to alleviate the high fat diet induced oxidative stress to protect the HFD fed $\mathrm{LDLR}^{-/-}$mice from developing aorta calcification. Since there is no commercial source of mouse S100A9/9 and AGE (advance glycated end produce), we used TNF- $a+$ S100A12 treated HASMC as a model system to test our hypothesis. We incubated HASMC with various dose of sitagliptin and found that sitagliptin was not toxic to HASMC as indicated by the cell proliferation rate (Fig. 3a). As previous found, combined TNF-a + S100A12 treatment up-regulated HASMC RAGE expression and calcification (Fig. 2c, 2d and 3b). Sitagliptin treatment appear to exert a does depend effect on suppressing the TNF-a + S100A12 induced calcification (Fig. 3b) $50 \mu \mathrm{M}$ of sitagliptin was as effective as $1000 \mu \mathrm{M}$ of $\mathrm{N}$-acetyl cysteine (NAC), in blunting the TNF-a + S100A12 induced calcification (Fig. 3b). Since one molecule of antioxidant can only neutralize one molecule of ROS, thus, we suspect that sitagliptin may be functioning as a noncompetitive NADPH oxidase inhibitor or it prevent the activation of NADPH activation. We found that siRNA for RAGE significantly lowered the TNF- $a+$ S100A12 induced RAGE (Fig. 3b) and calcification without affecting TNF receptor (TNFR) expression (Fig. 3c). As with siRNA for RAGE, we found that sitagliptin treatments blunted the TNF- $a+$ S100A12-induced RAGE expression but did not affect TNFR expression (Fig. 3c). The siRNA for TNFR-1 is very effective in blunting the TNF- $a+S 100 A 12$ induced upregulation of the RAGE and TNFR-1 expression (Fig. 3b) and decreased calcification (Fig. 3c). It is reported that TNFR1-induced activation of the classical NF-KB pathway [36], p65 shRNA downregulation RAGE protein accumulation [37] and Vascular remodeling and arterial calcification are directly mediated by S100A12 (EN-RAGE) [19]. These finding suggests that the cross talk between RAGE/S100A12 signaling and NF-KB pathway stimulate HASMC RAGE expression which lead to cell calcification. Sitagliptin may disrupt the cross talk between RAGE signaling and NF-KB either by inhibiting NADPH oxidase activity or preventing it from being activated to blunt the effect of TNF-a + S100A12 on upregulation of RAGE expression.

\section{Sitagliptin blunts TNF- $a+$ S100A12-induced HASMC oxidative stress, osteogenic markers expression, and}




\section{calcification}

Activated-RAGE promoted NADPH oxidase activity [38] which leading to generation of intracellular $\mathrm{H} 2 \mathrm{O} 2$ in vascular SMCs, endothelial cells, and fibroblasts [39] Oxidative stress plays a crucial role in RAGE signaling to trigger artery calcification [12]. It was suggested that RAGE pathway involved NADPH oxidase. We hypothesized that sitagliptin disrupted the cross talk between RAGE signaling and NF-KB either by inhibiting NADPH oxidase activity or preventing the activation of NADPH oxidase. If this this hypothesis is true, then, TNF- $a+$ S100A12 treatment should induce oxidative stress and sitagliptin should effectively attenuate the TNF- $a+S 100 A 12$ induced oxidative stress. Experimental data showed that TNF$a+$ S100A12 treatment stimulated the hydrogen peroxide production in HASMC (Fig. 4a). Sitagliptin, NAC and APO all were found to attenuate the TNF- $a+$ S100A12 treatment effect on HASMC hydrogen peroxide generation (Fig. 4a). As we found in previous experiment, $100 \mu \mathrm{M}$ of Sitagliptin as effective as the 500 $\mu \mathrm{M}$ APO in reducing the TNF- $\mathrm{a}+\mathrm{S} 100 \mathrm{~A} 12$-induced oxidative stress (Fig. 4a). These findings support our hypothesis that sitagliptin is unlikely to reduce the TNF- $\mathrm{a}+\mathrm{S} 100 \mathrm{~A} 12$ treated $\mathrm{HASMC} \mathrm{H}_{2} \mathrm{O}_{2}$ production by directly neutralizing the ROS produced by NADPH oxidase. We investigated 1) if TNF- $a+S 100 A 12$ treatment stimulates HASMC NADPH oxidase and NF-KB activation 2) if Sitagliptin reduces the NADPH oxidase and NF-KB activation. We found that TNF- $a+$ S100A12 increased HASMC NADPH oxidase activity, presumably, by promoting NADPH oxidase activation (Fig. 4b). One hundred micromolar (100 $\mu \mathrm{M}$ ) of sitagliptin was as effective as $500 \mu \mathrm{M}$ of apocynin (APO), a NADPH oxidase inhibitor, in suppressing the TNF- $a+$ S100A12 treated HASMC NADPH oxidase activity (Fig. 4B). These results showed that TNF- $\mathrm{a}+\mathrm{S} 100 \mathrm{~A} 12$ stimulate the HASMC NADPH oxidase activation and sitagliptin may either inhibit the NADPH oxidase activity or by blocking TNF- $a+$ S100A12 from activating NADPH oxidase activation to attenuate the superoxide generation in HASMCs NADPH oxidase (Nox) consists of membrane-bound (gp91phox and p22phox) and cytosolic components (p47phox, p67phox, p40phox, and Rac proteins). Nox activation requires the translocation of the cytosolic component p47phox to the cell membrane. Figure $4 \mathrm{~b}$ showed the HASMC membrane NADPH oxidase activity of the control HASMC (no treatment) or cells been treated with TNF- $a+$ S100A12, TNF- $a+$ S100A12 + Apo or TNF- $a+$ S100A12 + sitagliptin for a day. Apo and sitagliptin were very effective in inhibiting the HASMC cell membrane NADPH oxidase activity (Fig. 4b). APO was found to blunt the TNF- $a+S 100 A 12$ treatment induced migration of cytosolic P65 to the cell nucleus (Fig. 4c). As with APO, sitagliptin also blunted the TNF- $a+$ S100A12-induced migration of cytosolic P65 and P47 (Fig. 4c and 4d). Our data indicated that both Apo and sitagliptin attenuated the TNF- $\mathrm{a}+\mathrm{S} 100 \mathrm{~A} 12$ induced activation of NF-KB and the resultant NADPH oxidase activation. Thus, both Apo and sitagliptin should be capable of disrupting the literature proposed cross talk between RAGE signaling and NF-KB. Thus, we investigated if 1) TNF- $a+S 100 A 12$ treatment promotes HASMC transgenic markers expression and calcium deposit, and 2) if sitagliptin blunted the TNF- $a+$ S100A12 effect on HASMC osteogenic markers expression and cell calcium deposit. We found that TNF- $a+S 100 a 12$ treatment significantly up-regulated the HASMC osteogenic markers expression and calcium deposit (Fig. 5a and 5b). Sitagliptin significantly blunted the effect of TNF-a + S100A12 treatment on HASMC osteogenic markers expression and calcium deposit (Fig. 5a and 5b). Both APO and Sitagliptin were all very effective in blunting the impact of TNF- $a+$ S100A12 on RAGE expression and 
MSX-2 expression. (Fig. 5c). This finding suggests a possibility that a high level of antioxidant can block TNF-a without affecting RAGE expression.

If TNF-a up-regulate VSMC RAGE expression, then, the HFD fed LDLR ${ }^{-/-}$aorta should have a higher level of RAGE expression than the regular chow fed ones. In addition, orally administer sitagliptin should drastically reduce the HFD fed LDLR ${ }^{-/-}$mice aorta RAGE expression. We found that HFD feed $\mathrm{LDLR}^{-/-}$ mice indeed have a drastically higher the level of the RAGE expression in the medial layer of the upper descending aorta as indicated by the IHC staining (Fig. 5d). Orally administered sitagliptin significantly blunted the HFD induced up-regulation of RAGE expression (Fig. 5d).

\section{Discussion}

Sitagliptin, a DPP-4 inhibitor, was the first drug to be commercialized and approved for treatment of patients with type 2 diabetes mellitus (DM2) in Oct 2006 in USA and in 2007 by the European Medicines Agency at a dosage of $100 \mathrm{mg}$ daily[40]. Since hyperglycemia and dyslipidemia are two known risk factors of arterial calcification [41], sitagliptin, saxagliptin and alogliptin are commercially available DPP4 inhibitors which, in addition to lowering DM2 patients' blood glucose level, may also protect patients from cardiovascular diseases[40]. It has been reported that the presence of S100A12, a known RAGE agonist, drastically accelerated the development of artery atherosclerosis and artery calcification of regular chow fed Apo E -/- mice but S100A12 produced no effect on the Apo E +/+ mice [14]. Vascular smooth muscle cells (VSMC) isolated from the artery of the Apo E -/-S100A12 transgenic mice only develop elevated oxidative stress, expression of osteogenic marker expression and calcification when the VSMC were grown in a "conditioned media (cell culture media containing macrophage and serum isolated from hyperlipidemic APE -/-mice) [14]. These findings suggest that the ROS and/or inflammatory cytokines from the macrophages hyperlipidemic Apo E -/-activated may activate a mechanism which synergistically interacts with the RAGE/S100A12 signaling to stimulate artery atherosclerosis and calcification. One $\mu \mathrm{M}$ of APO or $10 \mu \mathrm{M}$ of DPI (diphenylene iodonium), two known NADPH oxidase inhibitor, effectively blunt the osteogenic marker expression and cell calcification in the "conditioned media" grown S100A12 transgenic Apo E -/-VSMC [14].

The authors concluded that RAGE/S100A12 signal induced aorta calcification is mediated by, at least in part, by NADPH oxidase. It was reported ureter ligation induced chronic kidney disease caused the S100A12 transgenic mice to develop oxidative stress and aorta calcification. The shame operation did not cause the S100A12 transgenic mice to develop aorta calcification. These findings suggest a possibility that CKD induced a mechanism that synergistically interact with the RAGE/S100 signal to stimulate aorta calcification. The ureter ligation produced no effect on the wild type mice [19].

Inclusion of hydrogen peroxide and phosphate in the medium stimulated the VSMC from the wild type or S100A12 mice aorta to accumulate $\mathrm{Ca}$. The potency of $\mathrm{H}_{2} \mathrm{O}_{2}$ + phosphate on promoting VSMC is doubled by the presence of VSMC S100A12 [19]. Transecting the wild type VSMC with si RNA for Nox 1 produced no effect on the $\mathrm{H}_{2} \mathrm{O}_{2}$ treated cell calcium deposit, but siRNA for Nox 1 transfection significantly reduce 
S100A12 transgenic VSMC calcification [19]. These findings lead us to hypothesize that the ROS and/inflammatory cytokines in circulation, presumably from the macrophages and neutrophils activated by hyperlipidemia or hyperglycemia, activate VSMC NF-KB. The activated NF-KB causes VSMC to express osteogenic markers and up-regulate RAGE expression. The VSMC RAGE is activated by S100A or AGE to trigger the activation of NADPH oxidase. The ROS from the NADPH oxidase further activates NF-KB. This perpetual amplifying cross talk between RAGE signaling and NF-KB pathway leads to VSMC osteotransformation and artery calcification (SFig 1). If this hypothesis is true, then, incubating HASMC with TNF- $\alpha$ and S100A12 should stimulate RAGE expression, NADPH oxidase and NF-KB activation, osteogenic markers expression and cell calcium deposit. Experimental data confirm our speculation (Figs. 3, 4 and 5).

Sitagliptin was found to protect HFD fed LDLR ${ }^{-/-}$mice against artery calcification (Table 1 and Fig. 1). Dobrian et al reported that sitagliptin supplement reduced HFD fed wild type mice reduced mice body weights, improved animal glucose tolerance and reduced the level of inflammation cytokines in the adipose and pancreatic islet[42]. Based on typical mice feed intake, we calculated that we used a sitagliptin dose about 4 times lower than what was used in Dobrian et al study [42] yet we found that yet we found our sitagliptin dose is sufficient to lower the HFD fed LDLR ${ }^{-/-}$serum DPP4 activity and nitrotyrosin level (Fig. 1d and Table 1). Previous study from this laboratory showed that intraperitoneal injected APO and NAC are very effective in reducing the HFD fed $\mathrm{LDLR}^{-/-}$mice systemic oxidative stress and inflammation as indicated by serum nitrotyrosin and TNF-a level. They are also very effective in lowering aorta calcification without drastically improving the hyperglycemia and hyperlipidemia condition [30]. Those findings lead us to suspect there is a GLP-1 independent mechanism that, at least contributed in part, to the Apo and NAC protective effects against HFD induced aorta calcification. We further speculate that this GLP-1 independent mechanism may be related to their ability to prevent the accumulation of ROS from NADPH oxidase in VSMC by neutralizing the ROS or inhibiting NADPH oxidase activity. As with APO and NAC, we found that sitagliptin only produced modest improvements in hyperglycemia and hyperlipidemia conditions yet it drastically improve the systemic inflammation and oxidative stress and aorta calcification (Table 1, Figs. 1 and 6). We thus suspect that the protective effect of sitagliptin may, at least contributed in part, by blunting systemic ROS/inflammatory cytokines induced NF-KB activation or the cross talk between RAGE signaling and NF-KB pathway. We used a HASMC model to test our hypothesis. Sitagliptin and Apo were found to block the TNF-a + S100A12 induced upregulation of RAGE expression, NADPH oxidase and NF-KB activation, osteogenic markers expression and calcium deposit in a HSMC model (Figs. 3, 4, 5 and 6).

Based on literature and our data, we proposed that sitagliptin might attenuate RAGE/S100a12 signaling by inhibiting NADPH oxidase activation. The reduction of ROS production due to lowered NADPH oxidase activity lead to lowered NF-KB activation, thus, lowers stimulation of RAGE expression. As a result, sitagliptin blunts the perpetual cross talk between RAGE signaling and NF-KB pathway to lower the osteogenic markers expression and calcium deposit (Fig. 6). If TNF-a + S100A12 treated HASMC is a good model representing the pathological condition of the hyperlipidemia and hyperglycemic mice aorta, 
then, HFD fed LDLR ${ }^{-/-}$mice should have a higher level of RAGE expression than those on regular chow. Experimental data confirmed our speculation (Fig. 6d). Our finding of a correlation between aorta calcification and RAGE expression agrees with literature data. Wang et al reported that the aorta valve of apoE -/- mice have significantly higher expression levels of aorta RAGE and osteogenic markers and calcium deposit than the wild type mice [43].

We invested if GLP-1 attenuated TNF-a-induced HASMC calcium deposit (SFig 1), We found that GLP-1 did not blunt the TNF-a-induced MSAMC calcification. Our finding that Si RNA for TNF-R1 or RAGE blocked the TNF- $a+$ S100A12 induced RAGE expression and siRNA for RAGE significantly blunted the TNF- $a+$ S100A12 induced up-regulation of RAGE expression and calcium deposit (Fig. 3) lead us to conclude that GLP-1 does not blunt the cascade of events initiated by activation of TNFR or RAGE signaling. Since our animal study showed that sitagliptin drastically lowered the serum TNF-a level and aorta calcification of the HFD fed $\mathrm{LDLR}^{-/-}$mice without dramatically improvement in blood glucose level or blood lipid chemistry (Table 1), we suspect that protective effect of sitagliptin on lowering the circulatory inflammatory may be mainly due to improvement in glucose control or due to GLP-1 exerting anti-inflammatory effect on the HASMC. Multiple studies have shown that DPP-4 inhibitor increase DM2 patients' circulatory GLP-1 level and lowered the circulatory inflammatory cytokines level [44]. It is not clear to us if the effect of sitagliptin on lowering serum circulatory inflammatory cytokines is due to its impact on serum GLP-1 level or because sitagliptin exert a direct impact on macrophage, monocytes and neutrophils inflammatory cytokine expression.

\section{Conclusion}

In conclusion, our HASMC experiment showed the protective effect of sitagliptin against aorta calcification is contributed, at least in part, by 1 ) blocking the activation of HASMC membrane surface NADPH and 2) downregulation of RAGE expression and NF-KB activation (Fig. 6).

\section{Abbreviations}

Advanced glycation end products: AGEs

Apocynin: APO

Apolipoprotein-E: ApoE

Bone matrix protein: BMP

Diabetes mellitus: DM

Dipeptidyl peptidase-4: DPP4

Low-density lipoprotein receptor knockout: LDLR 
Msh homeobox 2: MSX2

Nicotinamide adenine dinucleotide phosphate: NADPH

Nicotinamide adenine dinucleotide phosphate oxidase: Nox

Nuclear factor (NF)-KB: NF-KB

Reactive oxygen species: ROS

Receptor for advanced glycation end products: RAGE

Runt related transcription factor 2: RUNX2

Smooth muscle cells: SMCs

Tumor necrosis factor: TNF

Type I glucagon-like peptide: GLP-1

\section{Declarations}

\section{Ethics approval and consent to participate}

All animal study protocols complied with the Guide for the Institutional Animal Care and Use Committee of Taipei Veterans General Hospital (IACUC no.2020-265, Taipei, Taiwan) and the Guide for the Care and Use of Laboratory Animals of the US National Institutes of Health (8th edition, 2011).

\section{Consent for publication}

Not applicable.

\section{Availability of data and materials}

The datasets used and/or analyzed during the current study are available from the corresponding author on reasonable request.

\section{Competing interests}

The authors declare that they have no competing interests.

\section{Funding}


This study was supported, in part, by research grants from Taipei Veterans General Hospital (V101C-178). These funding agencies had no influence on the study design, data collection or analysis, decision to publish, or preparation of the manuscript.

\section{Authors' contributions}

(1) CP and PH contributed to the conception and design of the study and acquisition of data, CY, and JS contributed to analysis and interpretation of data, (2) CP, CY and JS contributed to drafting the article or revising it critically for important intellectual content, (3) $\mathrm{CP}, \mathrm{PH}, \mathrm{JW}$ and SJ contributed to final approval of the version to be submitted. All authors read and approved the final version of the manuscript, and ensure it is the case.

\section{Acknowledgements}

Not applicable.

\section{References}

1. Mazzone T. Increased prevalence of significant coronary artery calcification in patients with diabetes. Diabetes Care. 2001;24(8):1508.

2. Everhart JE, Pettitt DJ, Knowler WC, Rose FA, Bennett PH. Medial arterial calcification and its association with mortality and complications of diabetes. Diabetologia. 1988;31(1):16-23.

3. Liu F, Zhong H, Liang JY, Fu P, Luo ZJ, Zhou L, Gou R, Huang J. Effect of high glucose levels on the calcification of vascular smooth muscle cells by inducing osteoblastic differentiation and intracellular calcium deposition via BMP-2/Cbfalpha-1 pathway. Journal of Zhejiang University Science B. 2010;11(12):905-11.

4. Wada T, McKee MD, Steitz S, Giachelli CM. Calcification of vascular smooth muscle cell cultures: inhibition by osteopontin. Circulation research. 1999;84(2):166-78.

5. New SE, Aikawa E. Molecular imaging insights into early inflammatory stages of arterial and aortic valve calcification. Circulation research. 2011;108(11):1381-91.

6. Chistiakov DA, Sobenin IA, Orekhov AN, Bobryshev YV. Mechanisms of medial arterial calcification in diabetes. Curr Pharm Design. 2014;20(37):5870-83.

7. Al-Aly Z, Shao JS, Lai CF, Huang E, Cai J, Behrmann A, Cheng SL, Towler DA. Aortic Msx2-Wnt calcification cascade is regulated by TNF-alpha-dependent signals in diabetic Ldlr-/- mice. Arterioscler Thromb Vasc Biol. 2007;27(12):2589-96.

8. Kay AM, Simpson CL, Stewart JA. Jr.: The Role of AGE/RAGE Signaling in Diabetes-Mediated Vascular Calcification. J Diabetes Res. 2016;2016:6809703. 
9. Leopold JA. Vascular calcification: Mechanisms of vascular smooth muscle cell calcification. Trends Cardiovasc Med. 2015;25(4):267-74.

10. Shao JS, Aly ZA, Lai CF, Cheng SL, Cai J, Huang E, Behrmann A, Towler DA. Vascular Bmp Msx2 Wnt signaling and oxidative stress in arterial calcification. Ann N Y Acad Sci. 2007;1117:40-50.

11. Tanikawa T, Okada Y, Tanikawa R, Tanaka Y. Advanced glycation end products induce calcification of vascular smooth muscle cells through RAGE/p38 MAPK. Journal of vascular research. 2009;46(6):572-80.

12. Wei Q, Ren X, Jiang Y, Jin H, Liu N, Li J. Advanced glycation end products accelerate rat vascular calcification through RAGE/oxidative stress. BMC Cardiovasc Disord. 2013;13:13.

13. Malmstedt J, Karvestedt L, Swedenborg J, Brismar K. The receptor for advanced glycation end products and risk of peripheral arterial disease, amputation or death in type 2 diabetes: a populationbased cohort study. Cardiovascular diabetology. 2015;14:93.

14. Hofmann Bowman MA, Gawdzik J, Bukhari U, Husain AN, Toth PT, Kim G, Earley J, McNally EM. S100A12 in vascular smooth muscle accelerates vascular calcification in apolipoprotein E-null mice by activating an osteogenic gene regulatory program. Arterioscler Thromb Vasc Biol. 2011;31(2):337-44.

15. Wang Z, Jiang Y, Liu N, Ren L, Zhu Y, An Y, Chen D. Advanced glycation end-product Nepsiloncarboxymethyl-Lysine accelerates progression of atherosclerotic calcification in diabetes. Atherosclerosis. 2012;221(2):387-96.

16. Sun L, Ishida T, Yasuda T, Kojima Y, Honjo T, Yamamoto Y, Yamamoto H, Ishibashi S, Hirata K, Hayashi Y. RAGE mediates oxidized LDL-induced pro-inflammatory effects and atherosclerosis in non-diabetic LDL receptor-deficient mice. Cardiovascular research. 2009;82(2):371-81.

17. Oesterle A, Bowman MA. S100A12 and the S100/Calgranulins: Emerging Biomarkers for Atherosclerosis and Possibly Therapeutic Targets. Arterioscler Thromb Vasc Biol. 2015;35(12):2496507.

18. Kierdorf K, Fritz G. RAGE regulation and signaling in inflammation and beyond. J Leukoc Biol. 2013;94(1):55-68.

19. Gawdzik J, Mathew L, Kim G, Puri TS, Hofmann Bowman MA. Vascular remodeling and arterial calcification are directly mediated by S100A12 (EN-RAGE) in chronic kidney disease. Am J Nephrol. 2011;33(3):250-9.

20. Drucker DJ. Dipeptidyl peptidase-4 inhibition and the treatment of type 2 diabetes: preclinical biology and mechanisms of action. Diabetes Care. 2007;30(6):1335-43.

21. Conarello SL, Li Z, Ronan J, Roy RS, Zhu L, Jiang G, Liu F, Woods J, Zycband E, Moller DE, et al. Mice lacking dipeptidyl peptidase IV are protected against obesity and insulin resistance. Proc Natl Acad Sci USA. 2003;100(11):6825-30.

22. Kazafeos K: Incretin effect: GLP-1, GIP, DPP4. Diabetes research and clinical practice 2011, 93 Suppl 1:S32-36. 
23. Scheen AJ. DPP-4 inhibitors in the management of type 2 diabetes: a critical review of head-to-head trials. Diabetes Metab. 2012;38(2):89-101.

24. Mita T, Katakami N, Yoshii H, Onuma T, Kaneto H, Osonoi T, Shiraiwa T, Kosugi $K$, Umayahara $Y$, Yamamoto T, et al. Alogliptin, a Dipeptidyl Peptidase 4 Inhibitor, Prevents the Progression of Carotid Atherosclerosis in Patients With Type 2 Diabetes: The Study of Preventive Effects of Alogliptin on Diabetic Atherosclerosis (SPEAD-A). Diabetes Care. 2016;39(1):139-48.

25. Mita T, Katakami N, Shiraiwa T, Yoshii H, Onuma T, Kuribayashi N, Osonoi T, Kaneto H, Kosugi K, Umayahara Y, et al. Sitagliptin Attenuates the Progression of Carotid Intima-Media Thickening in Insulin-Treated Patients With Type 2 Diabetes: The Sitagliptin Preventive Study of Intima-Media Thickness Evaluation (SPIKE): A Randomized Controlled Trial. Diabetes Care. 2016;39(3):455-64.

26. Ta NN, Schuyler CA, Li Y, Lopes-Virella MF, Huang Y. DPP-4 (CD26) inhibitor alogliptin inhibits atherosclerosis in diabetic apolipoprotein E-deficient mice. J Cardiovasc Pharmacol. 2011;58(2):157-66.

27. Zeng Y, Li C, Guan M, Zheng Z, Li J, Xu W, Wang L, He F, Xue Y. The DPP-4 inhibitor sitagliptin attenuates the progress of atherosclerosis in apolipoprotein-E-knockout mice via AMPK- and MAPKdependent mechanisms. Cardiovascular diabetology. 2014;13:32.

28. Salim HM, Fukuda D, Higashikuni Y, Tanaka K, Hirata Y, Yagi S, Soeki T, Shimabukuro M, Sata M. Teneligliptin, a dipeptidyl peptidase-4 inhibitor, attenuated pro-inflammatory phenotype of perivascular adipose tissue and inhibited atherogenesis in normoglycemic apolipoprotein-E-deficient mice. Vascul Pharmacol. 2017;96-98:19-25.

29. Choi SY, Ryu HM, Oh EJ, Choi JY, Cho JH, Kim CD, Kim YL, Park SH. Dipeptidyl peptidase-4 inhibitor gemigliptin protects against vascular calcification in an experimental chronic kidney disease and vascular smooth muscle cells. PloS one. 2017;12(7):e0180393.

30. Lin CP, Huang PH, Lai CF, Chen JW, Lin SJ, Chen JS. Correction: Simvastatin Attenuates Oxidative Stress, NF-kappaB Activation, and Artery Calcification in LDLR-/-Mice Fed with High Fat Diet via Down-regulation of Tumor Necrosis Factor-alpha and TNF Receptor 1. PloS one. 2016;11(1):e0148590.

31. Buhimschi CS, Baumbusch MA, Dulay AT, Oliver EA, Lee S, Zhao G, Bhandari V, Ehrenkranz RA, Weiner CP, Madri JA, et al. Characterization of RAGE, HMGB1, and S100beta in inflammation-induced preterm birth and fetal tissue injury. Am J Pathol. 2009;175(3):958-75.

32. Jensky NE, Criqui MH, Wright MC, Wassel CL, Brody SA, Allison MA. Blood pressure and vascular calcification. Hypertension. 2010;55(4):990-7.

33. Chen JS, Huang PH, Wang CH, Lin FY, Tsai HY, Wu TC, Lin SJ, Chen JW. Nrf-2 mediated heme oxygenase-1 expression, an antioxidant-independent mechanism, contributes to anti-atherogenesis and vascular protective effects of Ginkgo biloba extract. Atherosclerosis. 2011;214(2):301-9.

34. Mirza S, Hossain M, Mathews C, Martinez P, Pino P, Gay JL, Rentfro A, McCormick JB, Fisher-Hoch SP. Type 2-diabetes is associated with elevated levels of TNF-alpha, IL-6 and adiponectin and low levels 
of leptin in a population of Mexican Americans: a cross-sectional study. Cytokine. 2012;57(1):13642.

35. Das D, Gawdzik J, Dellefave-Castillo L, McNally EM, Husain A, Raman J, Hofmann Bowman MA. S100A12 expression in thoracic aortic aneurysm is associated with increased risk of dissection and perioperative complications. J Am Coll Cardiol. 2012;60(8):775-85.

36. Wajant $\mathrm{H}$, Scheurich P. TNFR1-induced activation of the classical NF-kappaB pathway. FEBS J. 2011;278(6):862-76.

37. Kang R, Hou W, Zhang Q, Chen R, Lee YJ, Bartlett DL, Lotze MT, Tang D, Zeh HJ. RAGE is essential for oncogenic KRAS-mediated hypoxic signaling in pancreatic cancer. Cell death disease. 2014;5:e1480.

38. Wautier MP, Chappey O, Corda S, Stern DM, Schmidt AM, Wautier JL. Activation of NADPH oxidase by AGE links oxidant stress to altered gene expression via RAGE. American journal of physiology Endocrinology metabolism. 2001;280(5):E685-94.

39. Griendling KK, Sorescu D, Ushio-Fukai M. NAD(P)H oxidase: role in cardiovascular biology and disease. Circulation research. 2000;86(5):494-501.

40. Karagiannis T, Boura P, Tsapas A. Safety of dipeptidyl peptidase 4 inhibitors: a perspective review. Therapeutic advances in drug safety. 2014;5(3):138-46.

41. Chen NX, Moe SM. Vascular calcification: pathophysiology and risk factors. Curr Hypertens Rep. 2012;14(3):228-37.

42. Dobrian AD, Ma Q, Lindsay JW, Leone KA, Ma K, Coben J, Galkina EV, Nadler JL. Dipeptidyl peptidase IV inhibitor sitagliptin reduces local inflammation in adipose tissue and in pancreatic islets of obese mice. American journal of physiology Endocrinology metabolism. 2011;300(2):E410-21.

43. Wang B, Cai Z, Liu B, Liu Z, Zhou X, Dong N, Li F. RAGE deficiency alleviates aortic valve calcification in $A p o E(-/-)$ mice via the inhibition of endoplasmic reticulum stress. Biochimica et biophysica acta Molecular basis of disease. 2017;1863(3):781-92.

44. Avogaro A, de Kreutzenberg S, Fadini G. Dipeptidyl-peptidase 4 inhibition: linking metabolic control to cardiovascular protection. Curr Pharm Design. 2014;20(14):2387-94.

\section{Figures}


a

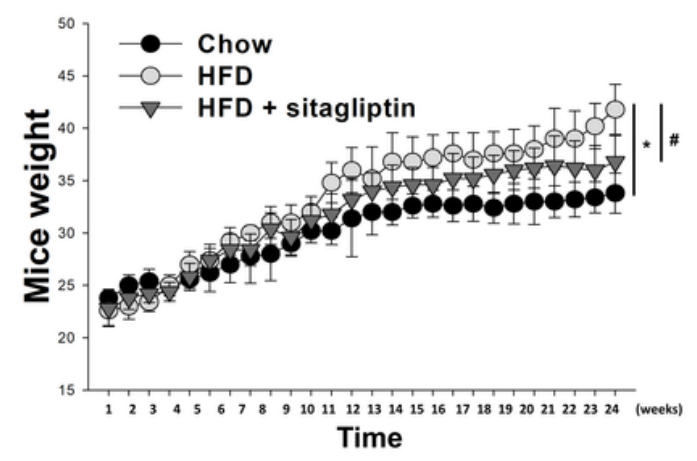

C

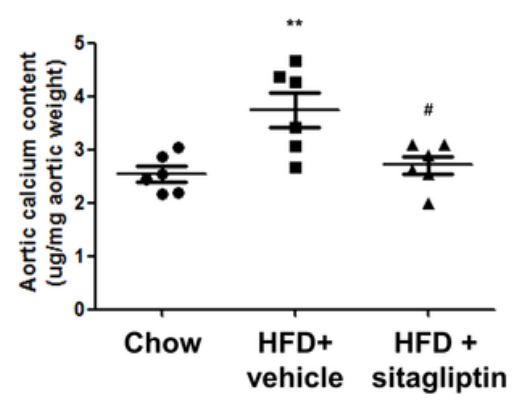

b

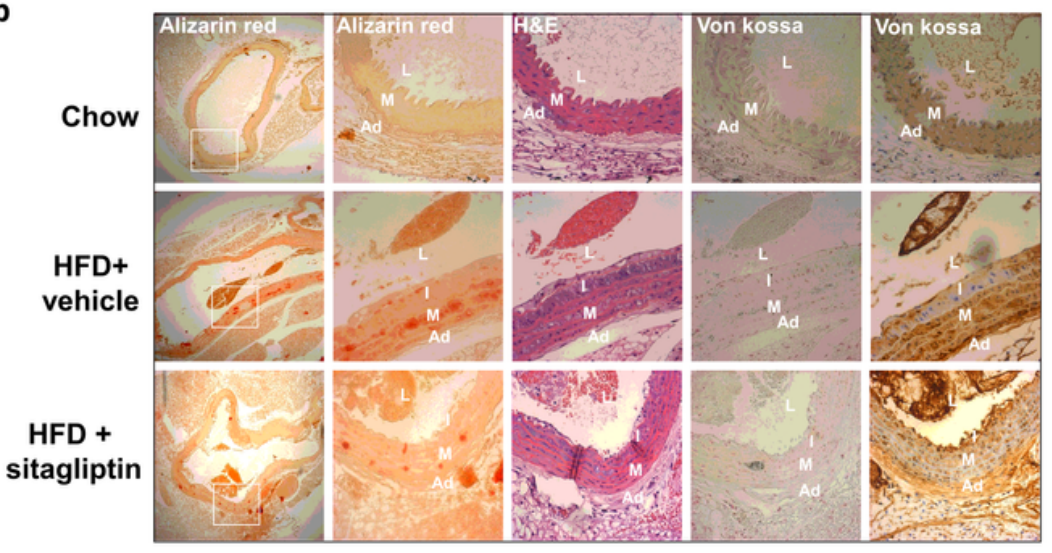

d

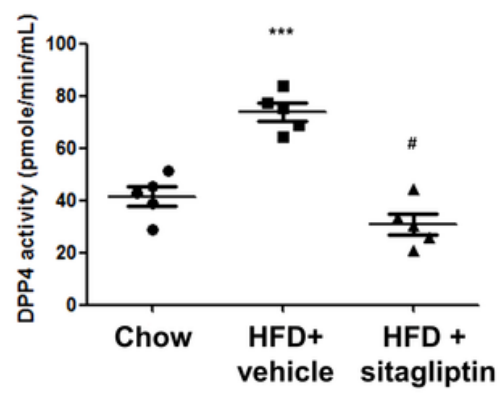

\section{Figure 1}

HFD promoted calcification, which was attenuated by sitagliptin, in male LDLR-/- mice. LDLR-/- mice were fed with a chow diet or HFD and simultaneously treated with sitagliptin (Sita, $100 \mathrm{mg} / \mathrm{kg} /$ day) for 6 months. (a) LDLR-/- mouse body weight was recorded weekly. (b) HFD-induced artery atherosclerotic plaque formation was detected by H\&E staining. HFD-induced artery calcification was detected by alizarin red staining. HFD promoted aortic calcification, which was dominant in the medial layer. The arrows point to the area of calcium deposition. The lumen showed blood cell remnants. L: Iumen, I: intima, M: media, and $\mathrm{A}$ : adventitia. (ND = 6, HFD = 6, and sitagliptin $=6$ ). LDLR-/- mice aorta were photographed at 100 and $400 \otimes$ magnifications. (c) Aortic calcium levels and (d) DPP4 activity were assayed. $* P<0.05$ compared with the chow group, and \#P $<0.05$ compared with the HFD groups (Aortic calcium levels; ND $=6, \mathrm{HFD}=11$, and sitagliptin $=6$. DPP4 activity were assayed $; \mathrm{ND}=5, \mathrm{HFD}=5$, and sitagliptin $=5$ ). 


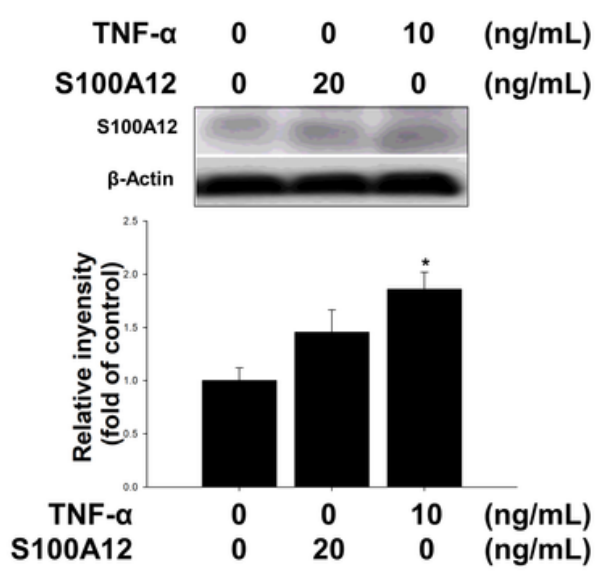

C

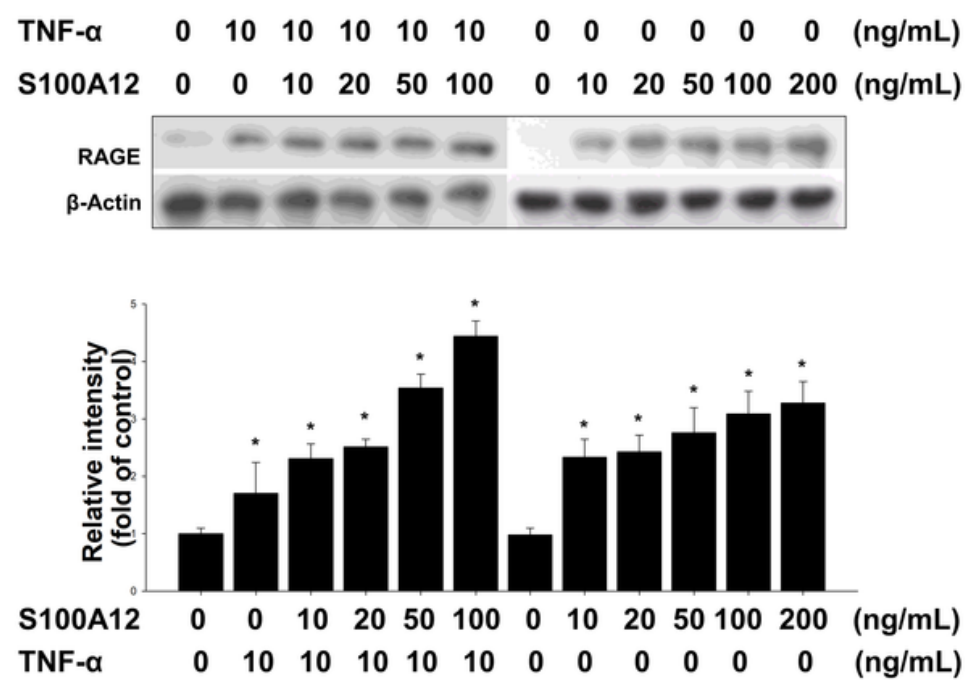

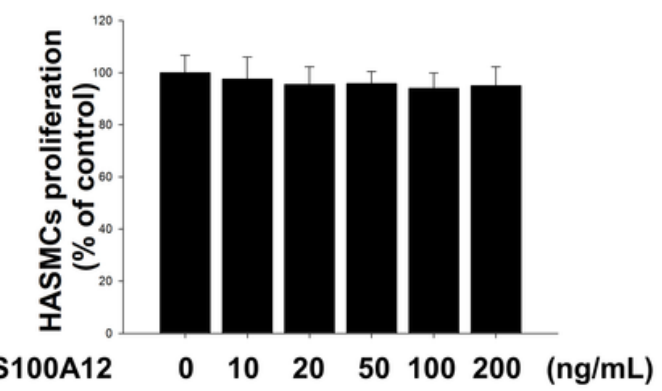

d

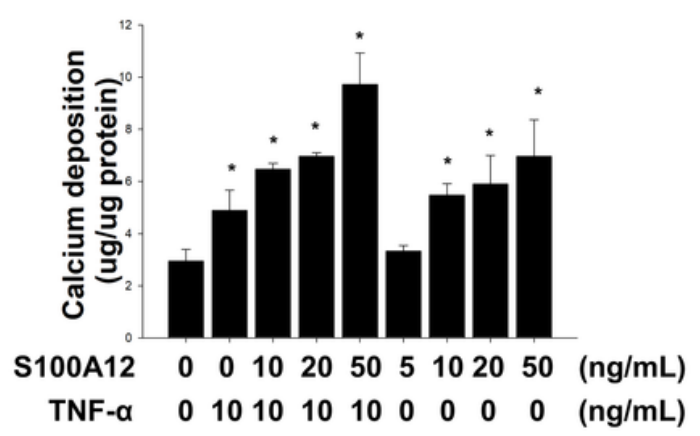

Figure 2

Effect of the combination of TNF-a with S100A12 on induced RAGE accumulation and calcium deposition in HASMCs. (a) The accumulation of S100A12 by TNF-a but not recombinant S100A12 in HASMCs was assayed. (b) The cytotoxicity effect of S100A12 was determined by MTT assay. (c) The induction of RAGE by S100A12 in HASMCs was determined by Western blotting assay. The accumulation of RAGE by combination of S100A12 with TNF-a in HASMCs was assayed. S100A12 enhanced TNF-ainduced RAGE protein accumulation in HASMCs. (d) HASMCs were cultured in osteogenic differentiation medium treatment with S100A12 for 4 days in the presence or absence of TNF-a. Calcium deposition was induced dose dependently by TNF-a for 4 days. $N=6$ for each set of experiments. ${ }^{*} \mathrm{P}<0.05$ compared with the control group. 


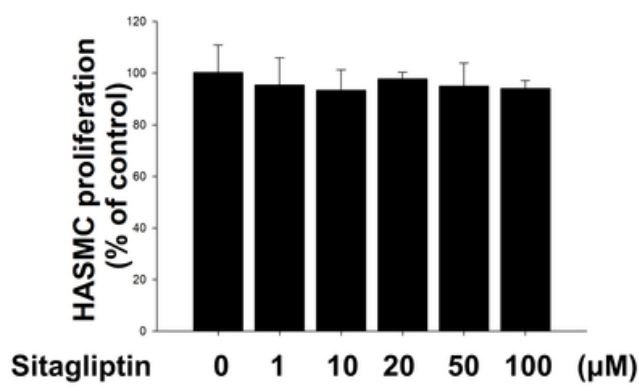

C

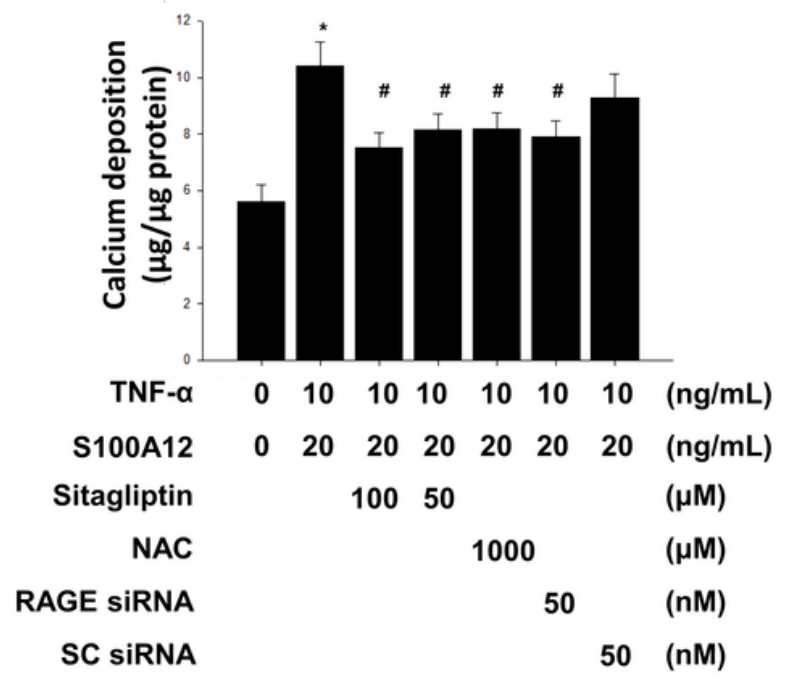

b
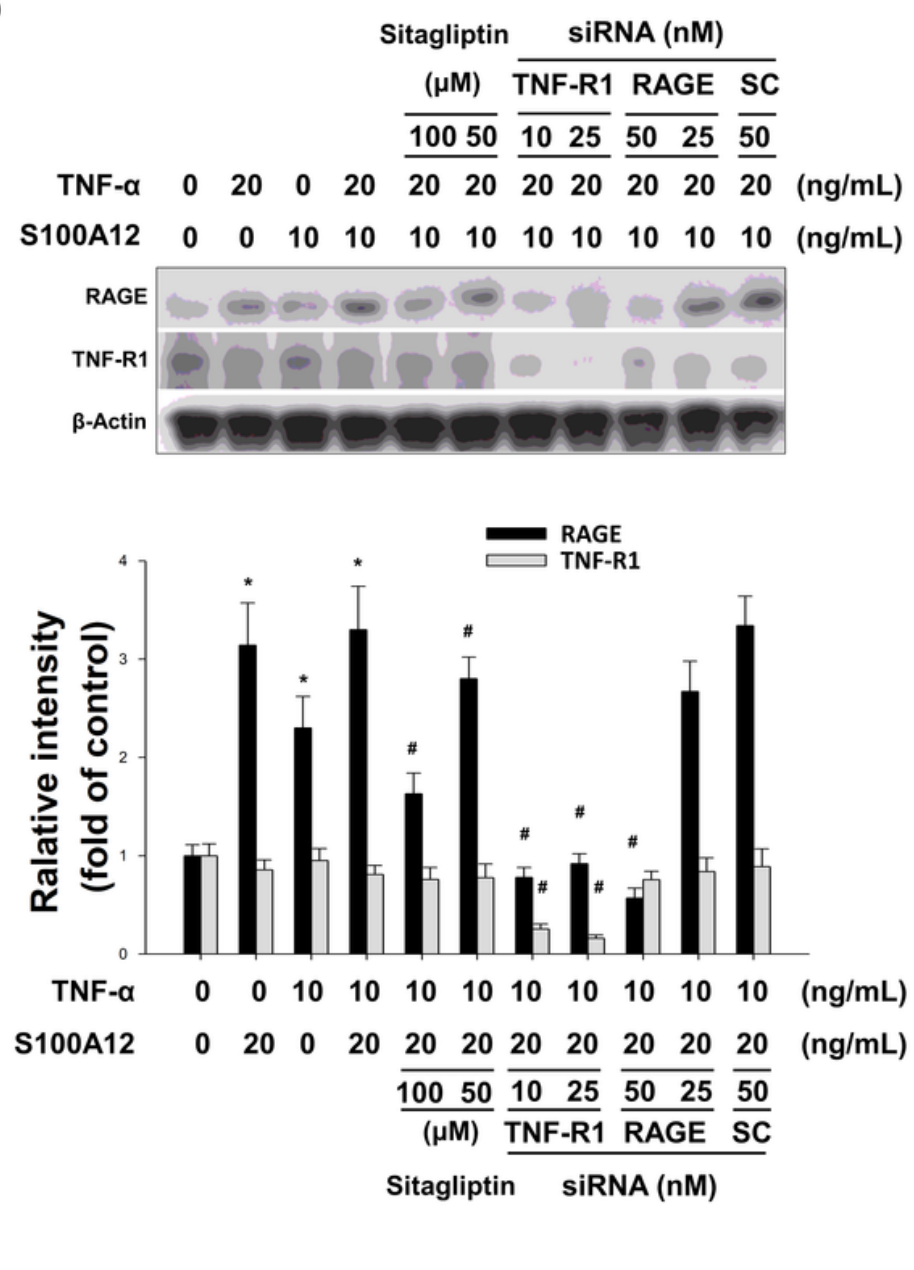

Figure 3

Sitagliptin attenuated TNF-a combination with S100A12-induced calcium deposition in HASMCs. (a) The cytotoxicity effect of sitagliptin was determined by MTT assay. (b) Sitagliptin and NAC attenuated the calcium deposition mediated by TNF-a combined with S100A12. The induction of RAGE protein accumulation by TNF-a combined with S100A12 in HASMCs was attenuated by sitagliptin. Western blotting assay showed the effects of the knockdown of TNFR1 and RAGE proteins by these siRNAs. Compared with the TNF-a combined with S100A12-stimulated cells in the presence of scrambled siRNAs, any combination of TNFR1 or RAGE siRNAs dramatically abolished TNF-a-stimulated calcification. *P < 0.05 compared with the control group, and \#P $<0.05$ compared with the TNF-a combined with S100A12 groups. $\mathrm{N}=6$ for each set of experiments. (c) Sitagliptin attenuated the calcium deposition mediated by TNF-a combined with S100A12. Suppressed RAGE accumulation in HASMCs and siRNAs against RAGEdownregulated calcium deposition (NAC: antioxidant agent, SC: scramble, TNF-R1: TNF-a receptor 1). 


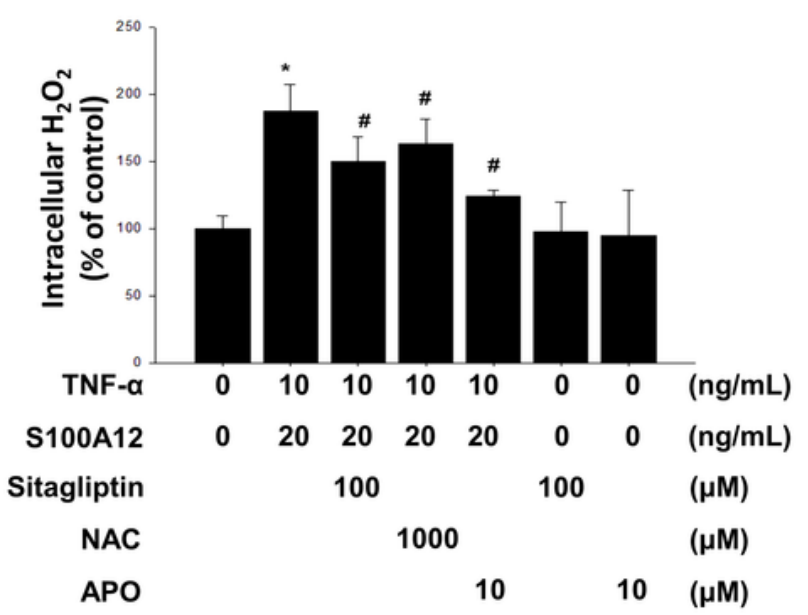

C

\begin{tabular}{|c|c|c|c|c|c|c|c|}
\hline Sitagliptin & 0 & 0 & 0 & 0 & 100 & 100 & $(\mu \mathrm{M})$ \\
\hline TNF- $\alpha$ & 0 & 0 & 20 & 20 & 0 & 20 & (ng/mL) \\
\hline S100A12 & 0 & 10 & 0 & 10 & 10 & 10 & (ng/mL) \\
\hline p65 & & 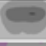 & $=$ & $\infty$ & $=$ & 0 & \\
\hline hnRNP c1/c2 & & - & $\theta$ & E & $\Leftrightarrow$ & 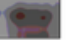 & Nucleus \\
\hline p65 & 0 & 0 & & & & 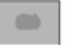 & \\
\hline$\beta$-Actin & & & & & & & \\
\hline
\end{tabular}

d b
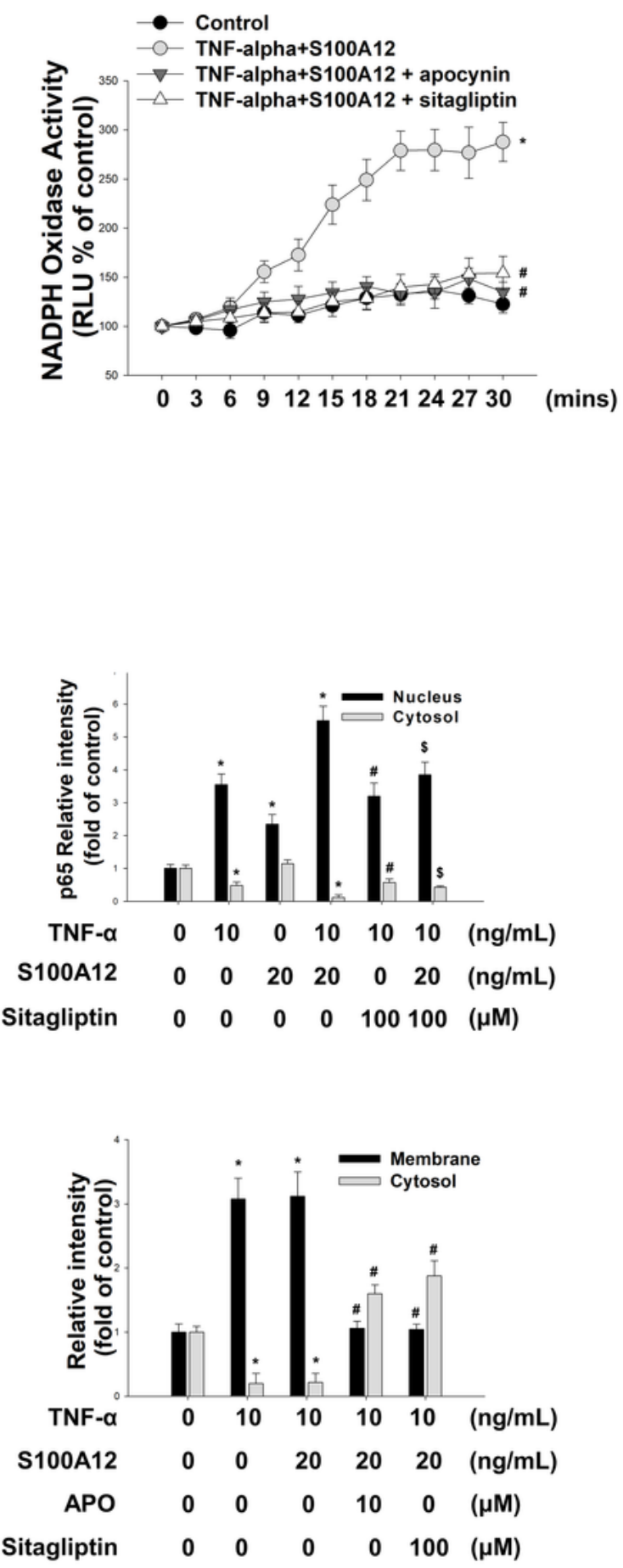

\section{Figure 4}

Sitagliptin attenuated TNF-a combination with S100A12-induced oxidative stress, NF-kB, and p47 activation in HASMCs. (a) HASMCs were cultured in osteogenic differentiation medium for 1 day in the presence or absence of TNF-a combined with S100A12 concomitantly with sitagliptin (50 $\mu \mathrm{M})$, APO (apocynin: $500 \mu \mathrm{M}$; Nox inhibitor). Intracellular hydrogen peroxide generation was assessed by DCF-AM staining (b) Nox activity was evaluated by lucigenin chemiluminescence. (c) The expression level of NF- 
KB subunit p65 (nucleus and cytosol fraction) was assessed by Western blotting. hnRNP c1/c2 was used as a nucleus fraction loading control. (d) The expression level of Nox subunit p47 (membrane fraction) was assessed by Western blotting. Caveoli- 1 was used as a membrane fraction loading control. * $\mathrm{P}<0.05$ compared with the control group, and \#P $<0.05$ compared with the TNF-a combined with S100A12 groups. $\mathrm{N}=6$ for each set of experiments.

a

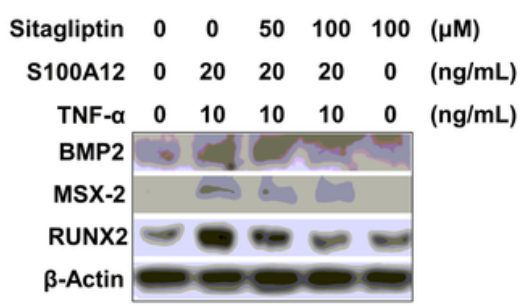

c

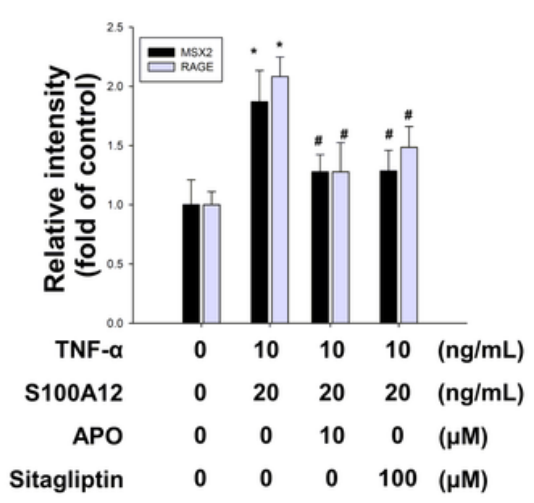

b

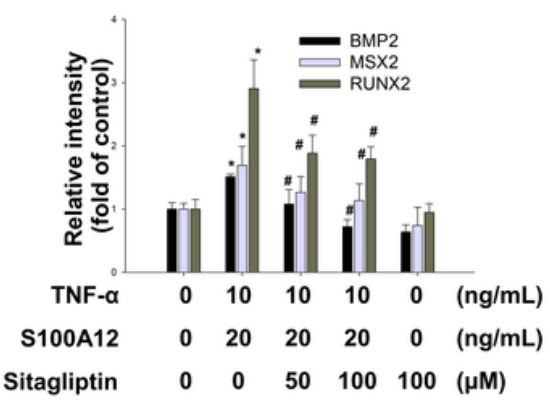

d

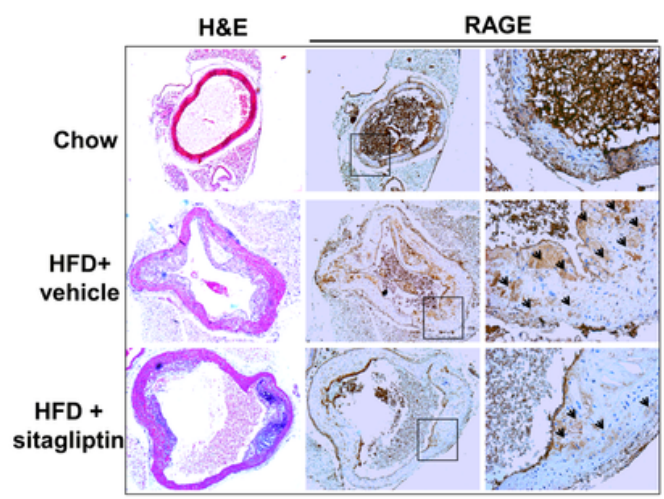

Figure 5

Sitagliptin modulated ROS generation and the expression of RAGE. (a) HASMCs were cultured in osteogenic differentiation medium for 1 day in the presence or absence of TNF-a combined with S100A12 and concomitantly with sitagliptin. Sitagliptin blocked the induction of MSX-2, BMP2, and RUNX2 accumulation induced by TNF-a combined with S100A12. (b) Antioxidant agents (NAC and APO) attenuated the TNF-a combined with S100A12-induced bone marker MSX-2 and (c) RAGE accumulation in HASMCs (sitagliptin; NAC: ROS scavenger; APO: Nox inhibitor). (d) Immunostaining of aortic RAGE showed that sitagliptin could significantly decrease the stimulatory effects of HFD on RAGE. Arrowhead indicates positive RAGE position. ${ }^{*} \mathrm{P}<0.05$ compared with the control group, and \#P $<0.05$ compared with the TNF-a combined with S100A12 groups. $N=6$ for each set of experiments.

\section{Supplementary Files}


This is a list of supplementary files associated with this preprint. Click to download.

- 20201212DPP4paperSuppFigureLegends.docx

- SF1.tif

- SF2.tif 